This is the author's final, peer-reviewed manuscript as accepted for publication. The publisher-formatted version may be available through the publisher's web site or your institution's library.

\title{
Two major cuticular proteins are required for assembly of horizontal laminae and vertical pore canals in rigid cuticle of Tribolium castaneum
}

Mi Young Noh, Karl J. Kramer, Subbaratnam Muthukrishnan, Michael R. Kanost, Richard W. Beeman, Yasuyuki Arakane

\section{How to cite this manuscript}

If you make reference to this version of the manuscript, use the following information:

Noh, M. Y., Kramer, K. J., Muthukrishnan, S., Kanost, M. R., Beeman, R. W., \& Arakane, Y. (2014). Two major cuticular proteins are required for assembly of horizontal laminae and vertical pore canals in rigid cuticle of Tribolium castaneum. Retrieved from http://krex.ksu.edu

\section{Published Version Information}

Citation: Noh, M. Y., Kramer, K. J., Muthukrishnan, S., Kanost, M. R., Beeman, R. W., \& Arakane, Y. (2014). Two major cuticular proteins are required for assembly of horizontal laminae and vertical pore canals in rigid cuticle of Tribolium castaneum. Insect Biochemistry and Molecular Biology, 53, 22-29.

Copyright: @ 2014 Elsevier Ltd.

Digital Object Identifier (DOI): doi:10.1016/j.ibmb.2014.07.005

Publisher's Link: http://www.sciencedirect.com/science/article/pii/S0965174814001179

This item was retrieved from the K-State Research Exchange (K-REx), the institutional repository of Kansas State University. K-REx is available at http://krex.ksu.edu 
For: Insect Biochemistry and Molecular Biology

Correspondence to:

Yasuyuki Arakane

Department of Applied Biology

Chonnam National University

300 Yongbong-dong, Buk-gu,

Gwangju 500-757, Korea

Phone: +82-62-530-0271

Fax: +82-62-530-2069

arakane@chonnam.ac.kr

Running Head: Noh et al. / Insect Biochemistry and Molecular Biology

Two major cuticular proteins are required for assembly

of horizontal laminae and vertical pore canals in rigid cuticle of Tribolium castaneum

Mi Young Noh ${ }^{\mathrm{a}}$, Karl J. Kramer ${ }^{\mathrm{b}}$, Subbaratnam Muthukrishnan ${ }^{\mathrm{b}}$,

Michael R. Kanost ${ }^{\mathrm{b}}$, Richard W. Beeman ${ }^{\mathrm{c}}$, Yasuyuki Arakane ${ }^{\mathrm{a} *}$

${ }^{a}$ Department of Applied Biology, Chonnam National University, 300 Yongbong-dong, Bukgu, Gwangju 500-757, Korea

${ }^{b}$ Department of Biochemistry and Molecular Biophysics, Kansas State University, Chalmers Hall, Manhattan, Kansas 66506, USA

${ }^{c}$ Department of Entomology, Kansas State University, Waters Hall, Manhattan, Kansas 66506, USA

*Corresponding author: Email to arakane@chonnam.ac.kr 


\section{Abstract}

The insect exoskeleton is composed of cuticle primarily formed from structural cuticular proteins (CPs) and the polysaccharide chitin. Two CPs, TcCPR27 and TcCPR18, are major proteins present in the elytron (highly sclerotized and pigmented modified forewing) as well as the pronotum (dorsal sclerite of the prothorax) and ventral abdominal cuticle of the red flour beetle, Tribolium castaneum. Both CPs belong to the CPR family, which includes proteins that have an amino acid sequence motif known as the Rebers \& Riddiford (R\&R) consensus sequence. Injection of double-stranded RNA (dsRNA) for $T c C P R 27$ and $T c C P R 18$ resulted in insects with shorter, wrinkled, warped and less rigid elytra than those from control insects. To gain a more comprehensive understanding of the roles of CPs in cuticle assembly, we analyzed for the precise localization of TcCPR27 and the ultrastructural architecture of cuticle in TcCPR27- and TcCPR18-deficient elytra. Transmission electron microscopic analysis combined with immunodetection using goldlabeled secondary antibody revealed that TcCPR 27 is present in dorsal elytral procuticle both in the horizontal laminae and in vertical pore canals. dsRNA-mediated RNA interference (RNAi) of $T c C P R 27$ resulted in abnormal electron-lucent laminae and pore canals in elytra except for the boundary between these two structures in which electron-dense molecule(s) apparently accumulated. Insects subjected to RNAi for TcCPR18 also had disorganized laminae and pore canals in the procuticle of elytra. Similar ultrastructural defects were also observed in other body wall regions with rigid cuticle such as the thorax and legs of adult $T$. castaneum. TcCPR27 and TcCPR18 are required for proper formation of the horizontal chitinous laminae and vertical pore canals that are critical for formation and stabilization of rigid adult cuticle. 
Keywords: Tribolium castaneum; cuticular protein; elytron; RNA interference (RNAi); transmission electron microscopy (TEM); pore canal. 


\section{Introduction}

Insect cuticle or exoskeleton is a complex biocomposite material consisting of three major morphologically distinct layers, the waterproofing envelope, the protein-rich epicuticle and the chitin/protein-rich procuticle (Locke, 2001; Moussian, 2010; Moussian et al., 2006). It provides a physical barrier against water loss and protects against physical damage, irradiation, xenobiotics and pathogens. Structural cuticular proteins (CPs) and the polysaccharide chitin are the major components of the exo- and endocuticular layers that comprise the procuticle. The former layer is formed before molting (pre-molt), whereas the latter is mainly deposited after completion of the molting process (post-molt). During cuticle maturation and tanning (sclerotization and pigmentation), CPs are post-translationally modified and cross-linked by quinones or quinone methides produced by the oxidation of $\mathrm{N}$ acylcatechols catalyzed by laccase 2 (Arakane et al., 2005; Hopkins and Kramer, 1992). This vital chemical process is required to stabilize and harden the cuticle, protecting insects from microbial, physical and environmental stresses. Although the factors contributing to the synthesis of cuticles with differing mechanical properties are not well understood, appropriate combinations and degrees of cross-linking of CPs as well as dehydration are required for determining the physical properties of the exoskeleton (Lomakin et al., 2011).

Bioinformatics searches of fully sequenced and annotated genomes of several insect species such as the honey bee, Apis melifera (Honeybee Genome Sequencing Consortium, 2006), the fruit fly, Drosophila melanogaster (Karouzou et al., 2007) and the red flour beetle, Tribolium castaneum (Dittmer et al., 2012; Richards et al., 2008) indicate that there is a large number of genes encoding CP-like proteins in insect genomes. Indeed, more than 200 putative $C P$ genes have been identified in the malaria mosquito, Anopheles gambiae (Cornman et al., 2008) and the silkworm, Bombyx mori (Futahashi et al., 2008). T. castaneum has 108 genes encoding CP-like proteins (Dittmer et al., 2012; Richards et al., 
2008).

Many of the insect structural CPs have been classified into 12 different families as defined by unique amino acid sequence motifs characteristic of each of the families (Willis, 2010; Ioannidou et al., 2014). The largest family is the CPR family whose members contain the Rebers \& Riddiford (R\&R) Consensus (Rebers and Riddiford, 1988). When amino acid sequences of proteins belonging to the CPR family are aligned, they fall into three groups denoted as RR-1, RR-2 and RR-3 based on sequence similarity (Andersen, 1998, 2000; Karouzou et al., 2007). CPR proteins containing the RR-1 motif have been found primarily in soft and flexible cuticles, while proteins with the RR-2 motif have been found mostly in rigid cuticles (Willis et al., 2005). CPR proteins with the RR-3 motif have been identified only in a few species (Andersen, 2000; Futahashi et al., 2008; Willis, 2010). Transcriptional regulation of $C P$ gene expression appears to be regulated by developmental and hormonal cues (Ali et al., 2013; Charles, 2010). Togawa et al. (2008) analyzed the temporal expression patterns of $152 C P R$ genes in A. gambiae by using real-time PCR. These were grouped into 21 clusters based on expression profiles. Interestingly, in B. mori larvae, several CP-like genes were primarily expressed in internal tissues (e.g. ovary, brain and posterior silk gland) rather than in the epidermis, and a few of the transcripts were detected only in the internal organs (Futahashi et al., 2008).

Although it is generally believed that CPs expressed at different developmental stages or in different body regions assemble a cuticle with appropriate mechanical properties such as rigidity or flexibility (Cox and Willis, 1985; Willis et al., 2005), the precise location of CPs within a cuticle is still not well determined. Very recently, Vannini et al. (2014) analyzed the expression of AgamCPF3 and AgamCPLCG3/4 proteins in A. gambiae and localized them using electron microscopic immunocytochemistry. The AgamCPF3 gene was highly 
expressed at the pharate adult stage, whereas maximal levels of transcripts of AgamCPLCG3/4 genes were detected in the young adult right after adult eclosion. The temporal expression of these three genes appears to be correlated with the locations of their products because the former is predominantly localized in the exocuticle, while the latter two are restricted to the endocuticle.

We previously identified two abundant cuticular proteins, TcCPR27 and TcCPR18, in elytra whose dorsal cuticle becomes highly sclerotized and pigmented to protect the underlying soft hindwings and dorsal abdominal portions of the T. castaneum adult (Arakane et al., 2012). These two proteins are members of the CPR family that contains the RR-2 motif. TcCPR27 and TcCPR18 proteins are abundant in rigid cuticles found in the elytron, pronotum and ventral abdomen but are absent or very minor in soft and flexible cuticles present in the dorsal abdomen and hindwing of T. castaneum (Arakane et al., 2012; Dittmer et al., 2012). dsRNA-mediated gene silencing (RNAi) of these proteins resulted in phenotypes with malformed and weakened elytra. In particular, the elytra of TcCPR27deficient adults were shorter, wrinkled, warped, fenestrated and less rigid than those of control insects, and the adults eventually died from dehydration approximately one week after eclosion. Those results revealed that these two major CPRs are structural proteins essential for formation and stabilization of the rigid cuticle of T. castaneum adults. However, ultrastructural changes in the cuticle after depletion of these proteins by RNAi have not been investigated so far. In this study we performed RNAi of these two $C P R$ genes in $T$. castaneum and analyzed the localization of TcCPR27 in cuticle by immunogoldhistochemistry as well as by transmission electron microscopy (TEM) of the ultrastructure of rigid cuticle from both TcCPR27- and TcCPR18-deficient adults. 


\section{Materials and methods}

\subsection{Insects}

T. castaneum (GA-1 strain) was used for this study. Insects were reared on organic flour at $30^{\circ} \mathrm{C}$ at $50 \%$ relative humidity (Beeman and Stuart, 1990). Under this rearing condition, adult eclosion occurs 5 days after pupation.

\subsection{RNA interference}

dsRNAs for $T c C P R 27$ and $T c C P R 18$ were synthesized as described previously (Arakane et al., 2012). One hundred ng of dsRNA was injected into late-stage larvae (a mixture of penultimate instar and last instar larvae), after which the phenotypes and morphology of the adult cuticle were analyzed approximately 13-17 days later when the insects had reached the pharate adult stage. dsRNA for the T. castaneum vermilion gene (dsTcVer) was injected as a negative control (Arakane et al., 2009; Lorenzen et al., 2002). Total RNA was isolated from whole insects (5 d-old pupae) after RNAi of TcCPR27, TcCPRI8 and TcCPR27/18 (co-injection) by using the RNeasy Mini kit, and then treated with DNase I (Qiagen). Three insects were pooled for each RNA extraction. One $\mu \mathrm{g}$ of total RNA was used to prepare cDNA using SuperScript III First-Strand Synthesis System (Invitrogen, Carlsbad, CA) according to the manufacturer's instructions. The detail of condition of real-time PCR was described in supplemental information. The total RNA was independently isolated for each of the three replications and significant differences were analyzed using the Student $t$-test. To estimate knockdown levels of the targeted proteins, soluble and insoluble proteins were extracted from elytra $(n=5)$ in cold phosphate-buffered saline (PBS) and analyzed 15\% SDS-PAGE as described previously (Arakane et al., 2012).

\subsection{Transmission electron microscopy}


Five day-old pupae that had been injected with dsRNA at the late larval stage of development were collected and fixed in a mixture of $0.1 \%$ glutaraldehyde and $4 \%$ paraformaldehyde in $0.1 \mathrm{M}$ sodium cacodylate buffer $(\mathrm{pH} 7.4)$ for $24 \mathrm{~h}$ at room temperature. Samples were rinsed three times for 15 min with $0.1 \mathrm{M}$ sodium cacodylate buffer, and then dehydrated in a progressive ethanol gradient of $50,60,70,80,90,95$ and $100 \%$ for 15 min each. The tissues were infiltrated in LR white resin (Electron Microscopy Sciences, PA, USA) (2:1 ethanol:resin for 4 h, 1:1 ethanol:resin for $4 \mathrm{~h}, 1: 2$ ethanol:resin for $4 \mathrm{~h}$ and $100 \%$ resin overnight). The tissues were vacuum-infiltrated for $2 \mathrm{~h}$, embedded in gelatin capsules (Electron Microscopy Sciences), and then polymerized at $55^{\circ} \mathrm{C}$ for $12 \mathrm{~h}$ followed by ultrathin sectioning. Ultrathin sections $(\sim 90 \mathrm{~nm})$ were stained with $4 \%$ aqueous uranyl acetate for 10 min and then imaged using a transmission electron microscope (JEM-1400, JEOL).

\subsection{Immunogold labeling}

To determine the precise location of the TcCPR27 protein in the rigid adult cuticle of $T$. castaneum, we performed immunogold labeling for TcCPR27. First, we extracted TcCPR27 protein from elytra of $5 \mathrm{~d}$-old pupae and purified by Ni-NTA chromatography as described previously (Arakane et al., 2012). Anti-TcCPR27 polyclonal antibodies were obtained from the yolk of purified TcCPR27-immuized hen's egg (Cocalico Biologicals, Inc., PA, USA). Ultrathin sectioned samples $(\sim 90 \mathrm{~nm})$ were blocked with $0.01 \mathrm{M}$ PBS (pH 7.4) containing $5 \%$ normal goat serum for $1 \mathrm{~h}$, and then incubated with anti-TcCPR27 antibodies (1:100) in $0.05 \mathrm{M}$ PBS containing 3\% nonfat milk and $0.02 \%$ TWEEN 20 overnight at $4{ }^{\circ} \mathrm{C}$. The tissues were rinsed with $0.01 \mathrm{M}$ PBS three times for $5 \mathrm{~min}$ each and $0.05 \mathrm{M}$ TBS (Tris-buffered saline) (pH 7.6) three times for 5 min each at room temperature followed by incubation with the secondary antibody conjugated with $6 \mathrm{~nm}$ gold particles (1:20) (goat anti-chicken $\operatorname{IgG}$ conjugated with $6 \mathrm{~nm}$ gold particles, Electron Microscopy Sciences) in 0.05 M TBS (pH 8.0) 
containing $0.05 \%$ fish gelatin (BBInternational, Cardiff, UK) for $2 \mathrm{~h}$ at room temperature. The tissues were washed with $0.05 \mathrm{M}$ TBS five times for $5 \mathrm{~min}$ each, deionized water three times for 5 min each at room temperature, and then stained with $4 \%$ aqueous uranyl acetate for $10 \mathrm{~min}$. 


\section{Results and Discussion}

\subsection{RNAi of TcCPR27 and TcCPR18}

We previously reported that injection of dsRNA for TcCPR27 and TcCPR18 genes into last instar larvae of $T$. castaneum resulted in phenotypes with malformed elytra (Arakane et al., 2012). The elytra from the dsTcCPR27-treated adults, in particular, were shortened, wrinkled and very fragile. To analyze the morphology of the rigid cuticle in adults deficient in either one or both of these CPR proteins, dsRNA for TcCPR27 and TcCPR 18 was injected into late-stage larvae, and the corresponding mRNA and protein levels were analyzed by realtime PCR and SDS-PAGE. The targeted gene products were substantially and specifically down-regulated at both the mRNA (Fig. 1A) and protein levels (Fig. 1B). Administration of a mixture of dsRNAs for both $T c C P R 27$ and $T c C P R 18(\mathrm{ds} T c C P R 27 / 18)$ significantly reduced the transcripts for both genes as was seen in animals treated with individual dsRNAs (Figs. $1 \mathrm{~A}$ and $1 \mathrm{~B})$.

Injection of dsTcCPR27, dsTcCPR18 and dsTcCPR27/18 into larvae had no effect on molting including the larval-larval, larval-pupal and pupal-adult molts. However, the elytra of the resulting adults were malformed and abnormal as reported previously (Arakane et al., 2012). The elytra of dsTcCPRI8 adults did not elongate fully and did not extend far enough to cover the entire abdomen. Furthermore, the elytra had a rough surface compared to that of control insects (Fig. 1C). The elytra of dsTcCPR27-treated adults exhibited more severe morphological defects than those of dsTcCPR18-depleted animals (Fig. 1C). Overall, these elytra were short, wrinkled, bumpy, warped and fenestrated. TcCPR27-deficient adults could not fold their hindwings properly probably due to the abnormal shape of their elytra. The elytra of dsTcCPR27/18-treated adults exhibited similar morphological defects, and they were even more pronounced than those of $T c C P R 27$-treated adults (Fig. 1C). The elytra, thoracic body wall and legs from these dsRNA-treated adults were collected and used to 
analyze the CP localization in adult rigid cuticle by immunohistochemistry and by TEM.

\subsection{TEM and immunolocalization of TcCPR27 in rigid cuticle}

Insect cuticle is composed of several morphologically distinct layers such as the envelope, epicuticle and procuticle (Locke, 2001; Moussian, 2010; Moussian et al., 2006). To gain a better understanding of the ultrastracture and morphology of rigid cuticle, we performed transmission electron microscopic (TEM) analysis of dorsal elytral, thoracic body wall and leg cuticles from pharate adults of T. castaneum (5-day old pupae). In both dorsal larval body wall cuticle and pharate adult elytral cuticle of $T$. castaneum, the envelope, epicuticle and procuticle consisting of numerous horizontally oriented chitinous laminae parallel to the epidermal cell apical plasma membrane were evident (Fig. 2). It should be noted that in the larval cuticle (left panel), there is a large number of somewhat twisted corkscrew-shaped structures that cross the horizontal laminae in a transverse direction in an apparently helical path. In the elytral procuticle, these structures are somewhat less twisted and appear to extend directly from the apical plasma membrane of the underlying epidermal cells and may be cytoplasmic extensions that penetrate the horizontal laminae and reach all the way to the epicuticle (right panel in Fig. 2). These vertical columnar structures are similar to those reported previously by Delachambre (1971) and are perhaps the same as the pore canals described by Locke (1961) and Wigglesworth (1985). They emerge from the apical plasma membrane and reach all the way to the epicuticle. However, we are uncertain if they contain or transport any lipid to the epicuticle. They have electron dense material at the edges and electron lucent fiber-like material in the middle, which appears white and is denoted as pore canal fibers (PCF). Similar vertical fibrillar structures or vertical fibrils have been observed previously after removal of minerals and proteins from the exoskeletons of crustaceans, such as Homarus americanus (American lobster), Callinectes sapidus (Atlantic 
blue crab) and Tylos europaeus (sand-burrowing isopod) and have been referred to as pore canals and pore canal fibers, respectively (Cheng et al., 2008; Seidl et al., 2011). Presumably, they are chitin fibrils. In T. castaneum adults, other regions with rigid cuticle such as thoracic body wall and legs also exhibited an ultrastructure very similar to that of the elytron (SFigs. 1A and 1E), while there are fewer horizontal laminae and no vertical PCFs in the regions with soft, flexible and less pigmented cuticle such as the dorsal abdomen, ventral elytra and hindwings (Fig. 3). The dense arrangement of numerous compact laminae and PCFs apparently contributes to the formation of rigid cuticle.

TcCPR27 is the most abundant cuticular protein extracted from elytra of $T$. castaneum adults, and it is also present in rigid cuticle of the pronotum and ventral abdomen as demonstrated by immunohistochemistry and confocal microscopy (Arakane et al., 2012). To determine a more precise localization of TcCPR27 protein in rigid cuticle, we carried out additional immunogold labeling for TEM. In elytra, TcCPR27 protein was detected throughout the procuticle but not in the epicuticle and envelope layers (Fig. 4A). The abundance of gold particles was drastically reduced in the rigid cuticle of dsTcCPR27-treated adults (Fig. 4B and SFigs. 2 and 3), indicating the high specificity of the antibody used to detect the TcCPR27 protein. At the interface between the apical surface of the epidermal cell and the procuticle, the plasma membrane protrudes (marked "apmp" for "apical plasma membrane protrusion" in Figs. 2, 4A and 5) into the endocuticle periodically. The cytoplasmic material contained within these apical protrusions that appear to eventually grow into pore canals lack horizontal laminae and PCFs. However, TcCPR27 and fiber-like structures surround the apical protrusions, suggesting that PCFs originate here and extend into the exocuticle. In the procuticle, TcCPR 27 is enriched in the highly electron-dense protein-rich regions of both the horizontal laminae and the vertical PCFs (Fig. 4B). A similar localization and distribution of TcCPR 27 protein were also observed in the procuticle of 
thoracic body wall (SFig. 2).

\subsection{Effect of RNAi for TcCPR27, TcCPR18 and TcVer on the morphology of horizontal laminae and vertical pore canals in rigid cuticle}

RNAi was also used to analyze the morphological and ultrastructural defects in the rigid cuticles of TcCPR27- and TcCPR18-depleted T. castaneum pharate adults (5 d-old pupae) and compared with the same cuticles from control (dsVer-treated) insects. The elytral cuticle from control dsTcVer-injected insects contained electron dense horizontal chitinprotein laminae and vertical pore canals containing a core of electron lucent PCFs (Figs. 5A, 5E and 5I). Electron lucent spacing at the boundary between the pore canals and the horizontal laminae may be derived from remnants of the plasma membrane invaginations of the procuticle during pore canal growth (Figs. 5A and 5I). Alternatively, this boundary may be a chitin-rich region. The chemical nature of the material at the boundary, however, is unknown.

After RNAi for TcCPR27, the number of immunogold particles was substantially reduced in the procuticle of pharate adults, indicating decreased expression of the CPR27 protein (Fig. 4B and SFigs. 2 and 3). The procuticle of elytra from dsTcCPR27-injected insects exhibited laminae that were more electron-lucent compared to those of dsTcVertreated insects (Figs. 5B and 5F). This was particularly evident in the pore canals, where the PCFs filled their entire width. The electron lucent regions of the horizontal laminae appear to be less compacted, disorganized and to occupy more space in the dsTcCPR27 RNAi elytra when compared with those from the dsTcVer-treated control insects. Morphology of the PCFs was also abnormal, exhibiting an amorphous fibrous structure that filled the entire pore canal lumen. These results support the hypothesis that TcCPR27 is critical for organizing the chitin fibrils into compact long, vertically oriented PCFs. The electron lucent fibers in the 
horizontal laminae and the vertical PCFs are most likely chitin-rich since injection of dsRNAs for neither $T c C P R 27$ nor $T c C P R 18$ had any effect on elytral chitin content per beetle (Arakane et al., 2012). Interestingly, the boundary separating the vertical PCFs embedded in the horizontal laminae becomes visibly more electron dense in elytra from dsTcCPR27treated insects (arrows in Figs. 5B and 5J). TcCPR18, the second most abundant cuticular protein in elytra, may contribute to this enhanced electron density because the electron dense boundary of the PCFs is not evident in elytra from dsTcCPR18- or dsTcCPR27/18-treated insects (Figs. 5C, 5K, 5D and 5L). We have previously performed dynamic mechanical analysis of elytra after RNAi of $T c C P R 27$ and reported that those elytra were significantly less rigid than elytra of dsTcVer-treated control insects (Arakane et al., 2012). The results presented here suggest that the depletion of TcCPR27 may have caused the accumulation of the other major CP, TcCPR18, in the boundary of the vertical PCFs where the protein may become improperly cross-linked. The absence of TcCPR27 and/or mislocalization of TcCPR18 may have led to the electron-lucent procuticle in elytra of dsTcCPR27-treated insects, whose cuticle is mechanically defective.

RNAi of the TcCPR18 gene also resulted in malformed elytra with irregular and rough surfacing compared to that of dsTcVer-injected control insects (Fig. 1C). Ultrastructural analysis of elytral cuticle from dsTcCPR18-injected insects revealed a disorganized and fuzzy horizontal laminar architecture as well as an abnormal shape and amorphous fibrous material in the vertical pore canals (Figs. 5C, 5G and 5K). Unlike the morphology of dsTcCPR27-injected animals, the electron dense boundary of the PCFs from dsTcCPR18-injected insects was not evident (Figs. 5C and 5K). Depletion of TcCPR18 protein produced by injection of $\mathrm{dsTcCPR} 18$ appears not to affect TcCPR27 protein localization. Like the result seen with dsTcVer-injected control insects, TcCRR27 was detected in both horizontal laminae and vertical PCFs of elytra from dsTcCPR18-injected 
insects (SFig. 3). Laminae and PCFs in the procuticle of elytra from dsTcCPR18-injected insects exhibited a relatively high electron density compared to those of dsTcCPR27-injected

insects. This result may have been due to an increased relative level of the most abundant rigid cuticle structural protein, TcCPR27. Even though we were unable to establish the localization of TcCPR18 protein in rigid cuticle of $T$. castaneum because of the lack of a specific antibody for that protein for use in immunohistochemical studies, the results of dsTcCPR18 RNAi experiments indicate that TcCPR18 is critical for proper laminar organization and PC formation in elytral cuticle.

Simultaneous depletion of the two most abundant rigid cuticular proteins, TcCPR27 and TcCPR18, by co-injection of dsRNAs for TcCPR27 and TcCPR18 (dsTcCPR27/18) resulted in disorganized electron-lucent horizontal laminae in elytral cuticle (Figs. 5D, 5H and 5L). The fibrous structure in the vertical PCFs was amorphous. However, in this case, the electron dense-rich boundary of the pore canals observed in $\operatorname{ds} T c C P R 27$-injected insects was not evident (Figs. 5D and 5L). Interestingly, the pore canals exhibited relatively high electron density compared to those of dsTcCPR27-injected insects. This may be due to accumulation of melanin-like pigment, free quinones or quinone methides produced by oxidation of catechols or due to aberrant cross-linking occurring with other cuticular proteins in the pore canals.

\subsection{Conclusions}

In this study we investigated the roles of TcCPR27 and TcCPR18, which are major structural proteins in elytral cuticle as well as other rigid cuticles of T. castaneum adults, in cuticular morphology and ultrastructure of the procuticle. Unlike the larval cuticle of this species, which is relatively soft and flexible, the dorsal elytral cuticle is highly sclerotized and pigmented, and is composed of not only the chitinous horizontal laminae but also a large 
number of vertical pore canals with PCFs in their core. This distinctive cuticle morphology is also observed in other body regions such as the thorax and legs, which become hardened and tanned in mature adults, suggesting that these proteins are critical in the assembly and stabilization of a lightweight and rigid cuticle for a beetle. TcCPR27 is present in both the horizontal laminae and vertical PCFs of the procuticle. Depletion of TcCPR27 and TcCPR18 proteins by RNAi resulted in a disorganized laminar architecture and amorphous PCFs, which results in short, wrinkled and weakened elytra. The ultrastructural defects produced by injection of dsTcCPR27, dsTcCPR18 and dsTcCPR27/18 in thorax and legs were similar to those in the elytral cuticle (SFig. 1). These results show that TcCPR27 and TcCPR18 have significant roles in the formation and morphology of the laminae and PCFs in the rigid and resilient cuticle of $T$. castaneum adults.

\section{Acknowledgements}

This work was supported by Basic Science Research Program through the National Research Foundation of Korea (NRF) funded by the Ministry of Education, Science and Technology (NRF-2012R1A2A1A01006467), and NSF grants IOS-1022227 and IOS-1257961 to SM and MK, respectively. 


\section{References}

Ali, M.S., Iwanaga, M., Kawasaki, H., 2013. Ecdysone-responsive transcriptional regulation determines the temporal expression of cuticular protein genes in wing discs of Bombyx mori. Gene. 512, 337-347.

Andersen, S.O., 1998. Amino acid sequence studies on endocuticular proteins from the desert locust, Schistocerca gregaria. Insect Biochem. Mol. Biol. 28, 421-434.

Andersen, S.O., 2000. Studies on proteins in post-ecdysial nymphal cuticle of locust, Locusta migratoria, and cockroach, Blaberus craniifer. Insect Biochem. Mol. Biol. 30, 569-577.

Arakane, Y., Lomakin, J., Beeman, R.W., Muthukrishnan, S., Gehrke, S.H., Kanost, M.R., Kramer, K.J., 2009. Molecular and functional analyses of amino acid decarboxylases involved in cuticle tanning in Tribolium castaneum. J. Biol. Chem. 284, 16584-16594.

Arakane, Y., Lomakin, J., Gehrke, S.H., Hiromasa, Y., Tomich, J.M., Muthukrishnan, S., Beeman, R.W., Kramer, K.J., Kanost, M.R., 2012. Formation of rigid, non-flight forewings (elytra) of a beetle requires two major cuticular proteins. PLoS Genet. 8, e1002682.

Arakane, Y., Muthukrishnan, S., Beeman, R.W., Kanost, M.R., Kramer, K.J., 2005. Laccase 2 is the phenoloxidase gene required for beetle cuticle tanning. P. Natl. Acad. Sci. U S A $102,11337-11342$.

Beeman, R.W., Stuart, J.J., 1990. A gene for lindane + cyclodiene resistance in the red flour beetle (Coleoptera: Tenebrionidae). J. of Econ. Entomol 83, 1745-1751.

Charles, J.P., 2010. The regulation of expression of insect cuticle protein genes. Insect Biochem. Mol. Biol. 40, 205-213.

Cheng, L., Wang, L., Karlsson, A., 2008. Image analyses of two crustacean exoskeletons and implications of the exoskeletal microstructure on the mechanical behavior. J. Mater. Res., $23,2854-2872$.

Consortium, H.G.S., 2006. Insights into social insects from the genome of the honeybee Apis mellifera. Nature 443, 931-949.

Cornman, R.S., Togawa, T., Dunn, W.A., He, N., Emmons, A.C., Willis, J.H., 2008. Annotation and analysis of a large cuticular protein family with the R\&R Consensus in Anopheles gambiae. BMC Genomics. 9, 22.

Cox, D.L., Willis, J.H., 1985. The cuticular proteins of Hyalophora cecropia from different anatomical regions and metamorphic stages. Insect Biochem. , 349-362. 
Delachambre, J., 1971. La formtion des canauxcutoiculaiores chezL'adulte de Tenebrio molitor L. : Etude ultrastructureale et remarques histochimiques. Tissue \& cell 3, 499520.

Dittmer, N.T., Hiromasa, Y., Tomich, J.M., Lu, N., Beeman, R.W., Kramer, K.J., Kanost, M.R., 2012. Proteomic and transcriptomic analyses of rigid and membranous cuticles and epidermis from the elytra and hindwings of the red flour beetle, Tribolium castaneum. J Proteome Res. 11, 269-278.

Futahashi, R., Okamoto, S., Kawasaki, H., Zhong, Y.S., Iwanaga, M., Mita, K., Fujiwara, H., 2008. Genome-wide identification of cuticular protein genes in the silkworm, Bombyx mori. Insect Biochem. Mol. Biol. 38, 1138-1146.

Hopkins, T.L., Kramer, K.J., 1992. Insect cuticle sclerotization. Annu. Rev. Entomol. 37, 273-302.

Ioannidou, Z.S., Theodoropoulou, M.C., Papandreou, N.C., Willis, J.H.,Hamodrakas, S.J. 2014. CutProtFam-Pred: Detection and classification of putative structural cuticular proteins from sequence alone, based on profile Hidden Markov Models. Insect Biochem. Mol. Biol. In press.

Karouzou, M.V., Spyropoulos, Y., Iconomidou, V.A., Cornman, R.S., Hamodrakas, S.J., Willis, J.H., 2007. Drosophila cuticular proteins with the R\&R Consensus: annotation and classification with a new tool for discriminating RR-1 and RR-2 sequences. Insect Biochem. Mol. Biol. 37, 754-760.

Locke, M., 1961. Pore canals and related structures in insect cuticle. The Journal of biophysical and biochemical cytology 10, 589-618.

Locke, M., 2001. The Wigglesworth Lecture: Insects for studying fundamental problems in biology. J. Insect. Physiol. 47, 495-507.

Lomakin, J., Huber, P.A., Eichler, C., Arakane, Y., Kramer, K.J., Beeman, R.W., Kanost, M.R., Gehrke, S.H., 2011. Mechanical properties of the beetle elytron, a biological composite material. Biomacromolecules. 12, 321-335.

Lorenzen, M.D., Brown, S.J., Denell, R.E., Beeman, R.W., 2002. Cloning and characterization of the Tribolium castaneum eye-color genes encoding tryptophan oxygenase and kynurenine 3-monooxygenase. Genetics. 160, 225-234.

Moussian, B., 2010. Recent advances in understanding mechanisms of insect cuticle differentiation. Insect Biochem. Mol. Biol. 40, 363-375.

Moussian, B., Seifarth, C., Muller, U., Berger, J., Schwarz, H., 2006. Cuticle differentiation during Drosophila embryogenesis. Arthropod Struct. Dev. 35, 137-152. 
Rebers, J.E., Riddiford, L.M., 1988. Structure and expression of a Manduca sexta larval cuticle gene homologous to Drosophila cuticle genes. J. Mol. Biol. 203, 411-423.

Richards, S., Gibbs, R.A., Weinstock, G.M., Brown, S.J., Denell, R., al., e., 2008. The genome of the model beetle and pest Tribolium castaneum. Nature. 452, 949-955.

Seidl, B., Huemer, K., Neues, F., Hild, S., Epple, M., Ziegler, A., 2011. Ultrastructure and mineral distribution in the tergite cuticle of the beach isopod Tylos europaeus Arcangeli, 1938. J Struct. Biol. 174, 512-526.

Togawa, T., Dunn, W.A., Emmons, A.C., Nagao, J., Willis, J.H., 2008. Developmental expression patterns of cuticular protein genes with the R\&R Consensus from Anopheles gambiae. Insect Biochem. Mol. Biol. 38, 508-519.

Vannini, L., Reed, T.W., Willis, J.H., 2014. Temporal and spatial expression of cuticular proteins of Anopheles gambiae implicated in insecticide resistance or differentiation of M/S incipient species. Parasit. Vectors. 7, 24.

Wigglesworth, V.B., 1985. The transfer of lipid in insects from the epidermal cells to the cuticle. Tissue \& cell 17, 249-265.

Willis, J.H., 2010. Structural cuticular proteins from arthropods: annotation, nomenclature, and sequence characteristics in the genomics era. Insect Biochem. Mol. Biol. 40, 189204.

Willis, J.H., Inconomidou, V.A., Smith, R.F., Hamodrakas, S.J., 2005. Cuticular proteins. In: Gilbert, L.I., Iatrou, K., Gill, S.S. (Eds). Comprehensive Molecular Insect Science, vol. 4. Elsevier, Oxford Vol. 4, 79-110. 


\section{Figure legends}

Fig. 1. RNAi for TcCPR27, TcCPR18 and TcCPR27/18. dsRNAs for TcCPR27 (dsCPR27), TcCPR18 (dsCPR18) and TcCPR27/18 (dsCPR27/18) (100 ng per insect) were injected into last instar and earlier stage larvae $(n=30)$ as described in the Methods section. The expression of $T c C P R 27$ and $T c C P R 18$ was analyzed by real-time PCR (A) and SDSPAGE. (B) cDNAs were prepared from total RNA isolated from 5 d-old pupae $(\mathrm{n}=3)$. Expression levels of $T c C P R 27$ and $T c C P R 18$ are presented relative to the levels in dsVerinjected control insects. The transcript levels of T. castaneum ribosomal protein S6 (TcRpS6) were measured to normalize for differences between samples in the concentrations of cDNA templates. Asterisks indicate a significant difference in transcript levels of $T c C P R 27$ or TcCPR18 between control and test samples $(p<0.005, t$-test $)$. Data are shown as mean $\pm \mathrm{SE}$ $(n=3)$. Proteins were extracted from five pairs of elytra from 5 d-old pupae for each treatment. Both $T c C P R 27$ and $T c C P R 18$ were significantly and specifically down-regulated at both the mRNA and protein levels after dsRNA injections. (C) Depletion of TcCPR27 or TcCPR18 proteins by injection of dsCPR27 and dsCPR18, respectively, resulted in malformed elytra. Elytra from the resulting adults that had been injected dsRNA for both genes (dsCPR27/18) exhibited morphological defects similar to, but more pronounced than those of dsCPR27-injected animals. dsRNA for TcVer (dsVer) was injected to serve as a negative control.

Fig. 2. Ultrastructure of larval body and adult elytral cuticles. Both larval and elytral cuticle are composed of distinct layers including the envelope, epicuticle and procuticle. The procuticle consists of a number of horizontal, chitinous laminae. In addition, there are numerous pore canals running transverse to the laminae in elytral cuticle, as well as to the 
apical plasma membrane. The canals extend from the apical plasma membrane to the epicuticle region and contain a core of pore canal fibers. ev, envelope; ep, epicuticle; pro, procuticle; $\mathrm{pc}=$ pore canal; pcf, pore canal fiber; apmp, apical plasma membrane protrusion. Scale bar $=2 \mathrm{~nm}$.

Fig. 3. Ultrastructure of dorsal abdominal, ventral elytral and hindwing cuticles. Dorsal abdominal, ventral elytral and hindwing cuticles are relatively soft, flexible and less pigmented in adult $T$. castaneum. Ultrastructure of these three cuticles from pharate adults (5 d-old pupae) was analyzed by TEM. Unlike in the rigid cuticle such as dorsal elytron, thorax body wall and leg, there are few horizontal laminae and no vertical PCF in soft cuticle. ev, envelope; ep, epicuticle; pro, procuticle; $\mathrm{pc}=$ pore canal. Scale bar $=200 \mathrm{~nm}$.

Fig. 4. Localization of TcCPR27 in procuticle of elytral dorsal cuticle. Ultra-thin sections $(90 \mathrm{~nm})$ of wild-type pharate adults (5 d-old pupae) (A) or pharate adults (5 d-old pupae) that had been injected with dsRNA for TcCPR27 (dsCPR27) or TcVer (dsVer) in the late larval stages (B) were incubated with anti-TcCPR27 antibody. Anti-TcCPR27 antibody was detected by secondary goat anti-chicken antibodies conjugated to $6 \mathrm{~nm}$ gold particles. In (A), the outer (2), inner (3) and middle (4) parts of elytral cuticle are enlarged. TcCPR27 is present in both horizontal laminae and vertical pore canal fibers within the procuticle, but not in the envelope and epicuticle. ev, envelope; ep, epicuticle; pcf, pore canal fiber; apmp, apical plasma membrane protrusion. Scale bar in panel $1=1 \mu \mathrm{m}$ and panels 2,3 and $4=200$ nm. In (B), TcCPR27 protein, like wild-type insects, is present in both the horizontal laminae and vertical pore canal fibers of elytral cuticle from dsVer-injected insects (left panels). The number of gold particles is drastically reduced in dsCPR27-injected insects (right panels), indicating that anti-TcCPR27 antibody specifically recognizes the TcCPR27 protein. Scale 
bar $=200 \mathrm{~nm}$.

Fig. 5. Ultrastructure of elytral cuticles from $T c C P R 27-, T c C P R 18$ - and TcCPR27/18deficient insects. Ultrastructure of elytral cuticle from pharate adults ( $5 \mathrm{~d}$-old pupae) that had been injected with dsRNA for $\operatorname{TcCPR27}(\mathrm{B}, \mathrm{F}$ and $\mathrm{J}), \operatorname{TcCPR} 18(\mathrm{C}, \mathrm{G}$ and $\mathrm{K}$ ), $\operatorname{TcCPR} 27 / 18(\mathrm{D}, \mathrm{H}$ and $\mathrm{L})$ and $\operatorname{TcVer}(\mathrm{A}, \mathrm{E}$ and $\mathrm{I})$ in the late larval instars was analyzed by TEM. Arrows in panels A and I indicate the spaces between the horizontal laminae and vertical pore canals (PC) in dsVer-injected insects. Arrows in panels B and $\mathrm{J}$ indicate electron-dense PC boundary in dsCPR27-injected insects. ev, envelope; ep, epicuticle; pro, procuticle; pcf, pore canal fiber; apmp, apical plasma membrane protrusion. Scale bar in A$\mathrm{D}=2 \mu \mathrm{m}$ and $\mathrm{E}-\mathrm{L}=200 \mathrm{~nm}$. 


\section{Supplementary Information}

\section{Materials and methods}

\section{Real-time PCR}

To analyze the knockdown levels after RNAi for $T c C P R 27, T c C P R 18$ or $T c C P R 27 / 18$, realtime PCR was performed using the Thermal Cycler Dice real-time PCR system (Takara). The following primer sets were used: 5'-AGG TTA CGG CCA TCA TCA CTT GGA-3' and 5'-ATT GGT GGT GGA AGT CAT GGG TGT-3' for TcCPR27, 5'-GAA TAC CGC ATC CGT GAC CAC AAA-3' and 5'-CAG GTT CCA ACA AAC TGT AGG TTC CC-3' for TcCPR18, and 5'-ACG CAA GTC AGT TAG AGG GTG CAT-3' and 5'-TCC TGT TCG CCT TTA CGC ACG ATA-3' for the T. castaneum ribosomal protein S6 (TcRpS6), with the latter used to normalize for differences between samples in the concentration of cDNA template (Arakane et al., 2008; Arakane et al., 2012). Real-time PCR was conducted in a 50 $\mu 1$ reaction mixture containing $1 \mu l$ template cDNA, $25 \mu$ SYBR Premix Ex Taq (Takara), $0.2 \mu \mathrm{M}$ of each primer with the program: initial denaturation at $95^{\circ} \mathrm{C}$ for $30 \mathrm{~s}$ followed by 40 cycles of $95^{\circ} \mathrm{C}$ for $5 \mathrm{~s}$ and $60^{\circ} \mathrm{C}$ for $30 \mathrm{~s}$. At the end of the PCR reaction, a melt curve was generated to evaluate the possibility of undesirable side-products.

\section{Figure Legends}

SFig. 1. Ultrastructure of thoracic and leg rigid cuticles from TcCPR27-, TcCPR18- and TcCPR27/18-deficient insects. Ultrastructure of thoracic (top panels) and leg (bottom panels) cuticle from pharate adults (5 d-old pupae) that had been injected dsRNA for $T c C P R 27(\mathrm{~B}$ and F), TcCPR18 (C and G), TcCPR27/18 (D and H) and TcVer (A and E) in the late instar larvae was analyzed by TEM. Arrows in panels A and E indicate the spaces 
between the horizontal laminae and vertical pore canals in dsVer-injected insects. Arrows in panels $\mathrm{B}$ and $\mathrm{F}$ indicate electron-dense $\mathrm{PC}$ boundary in dsCPR27-injected insects. The ultrastructural defects produced by injection of dsCPR27, dsCPR18 and dsCPR27/18 in thorax and leg cuticle were similar to those of the elytral procuticle, suggesting that TcCPR27 and TcCPR18 are critical for formation of rigid cuticle of $T$. castaneum adults. pcf, pore canal fiber. Scale bar $=500 \mathrm{~nm}$.

SFig. 2. Immunolocalization of TcCPR27 in thoracic cuticle. Ultra-thin sections (90 nm) of pharate adults (5 d-old pupae) that had been injected with dsRNA for $T c C P R 27$ (dsCPR27) or TcVer (dsVer) in late instar larvae were incubated with anti-TcCPR27 antibody. Anti-TcCPR27 antibody was detected by secondary goat anti-chicken antibody conjugated to $6 \mathrm{~nm}$ gold particles. Like in the elytral cuticle (see Fig. 3), TcCPR27 protein is present in both horizontal laminae and in vertical pore canals of the thoracic cuticle from dsVer-injected insects (left panels). The number of gold particles is drastically reduced in dsCPR27-insects (right panels). Scale bar $=200 \mathrm{~nm}$.

SFig. 3. Localization of TcCPR27 in elytra from TcCPR18-deficient insects. Ultra-thin sections $(90 \mathrm{~nm})$ of pharate adults (5 d-old pupae) that had been injected dsRNA for TcCPR27, TcCPR18, TcCPR27/18 (co-injection) or TcVer in late instar larvae were incubated with anti-TcCPR27 antibody. Anti-TcCPR27 antibody was detected by secondary antibody conjugated to $6 \mathrm{~nm}$ gold particles. TcCPR27 protein is present in both horizontal laminae and in vertical pore canals of elytral cuticle from dsVer-and dsCPR18-injected insects, but it is depleted in those from dsCPR27- and dsCPR27/18-injected insects. Scale bar $=200 \mathrm{~nm}$. 
Fig. 1

A
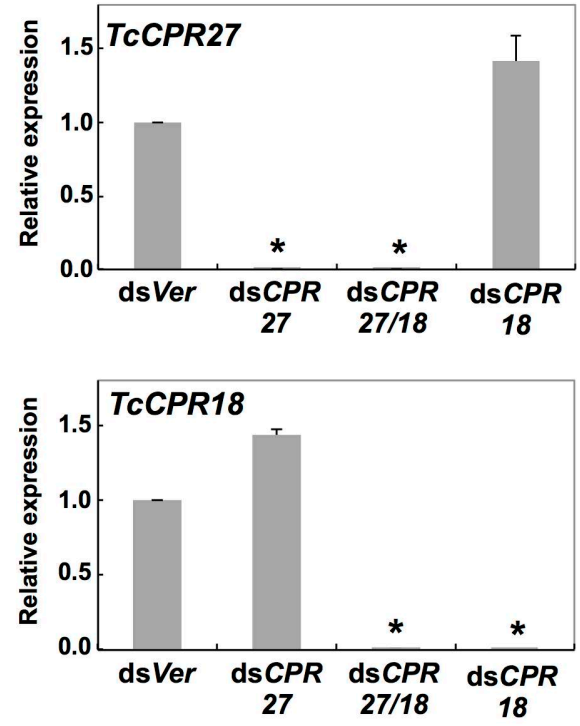

B
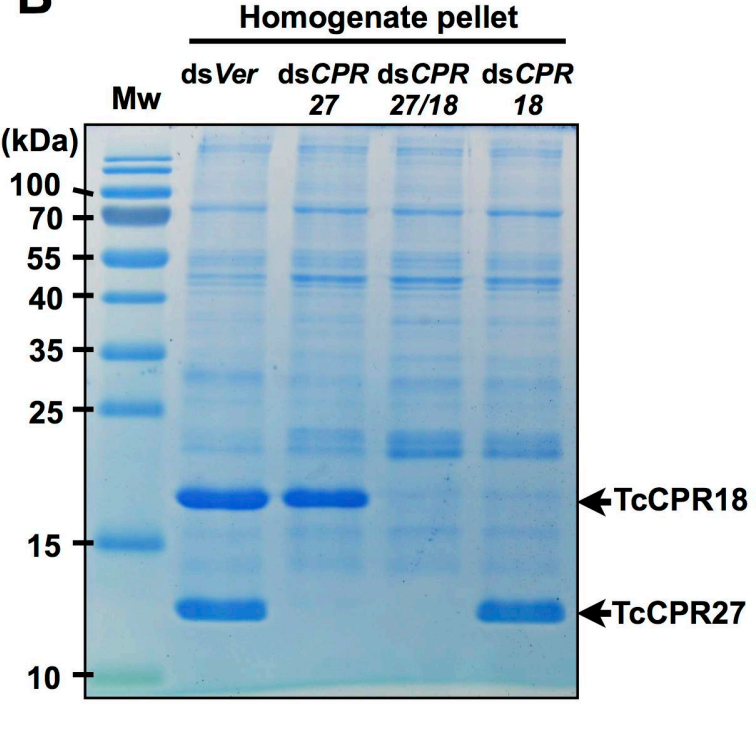

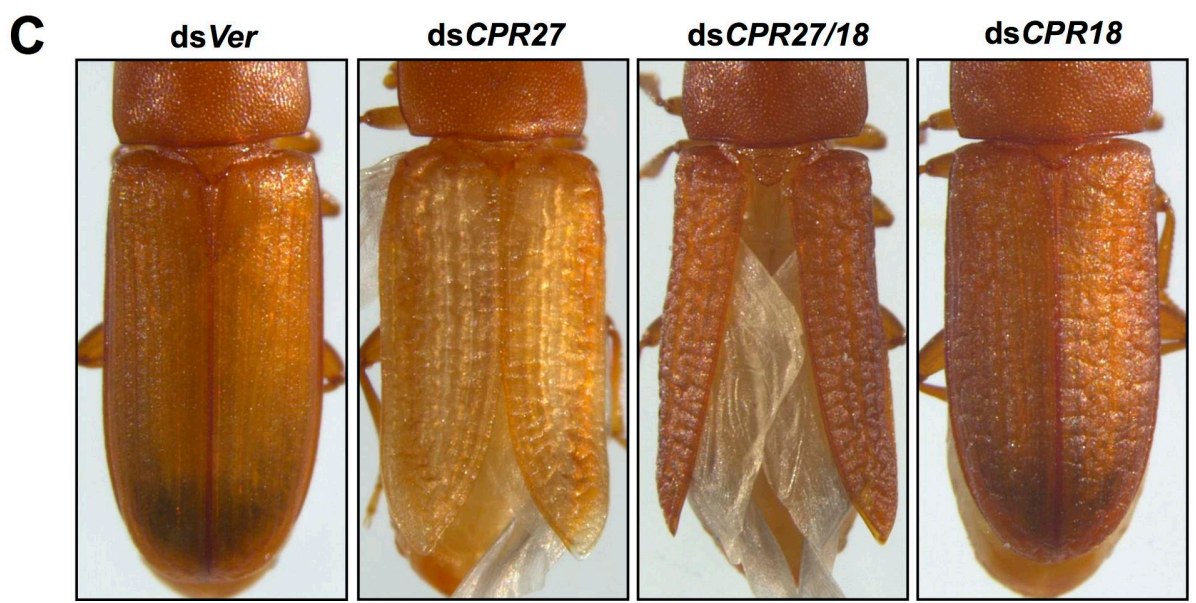


Fig. 2

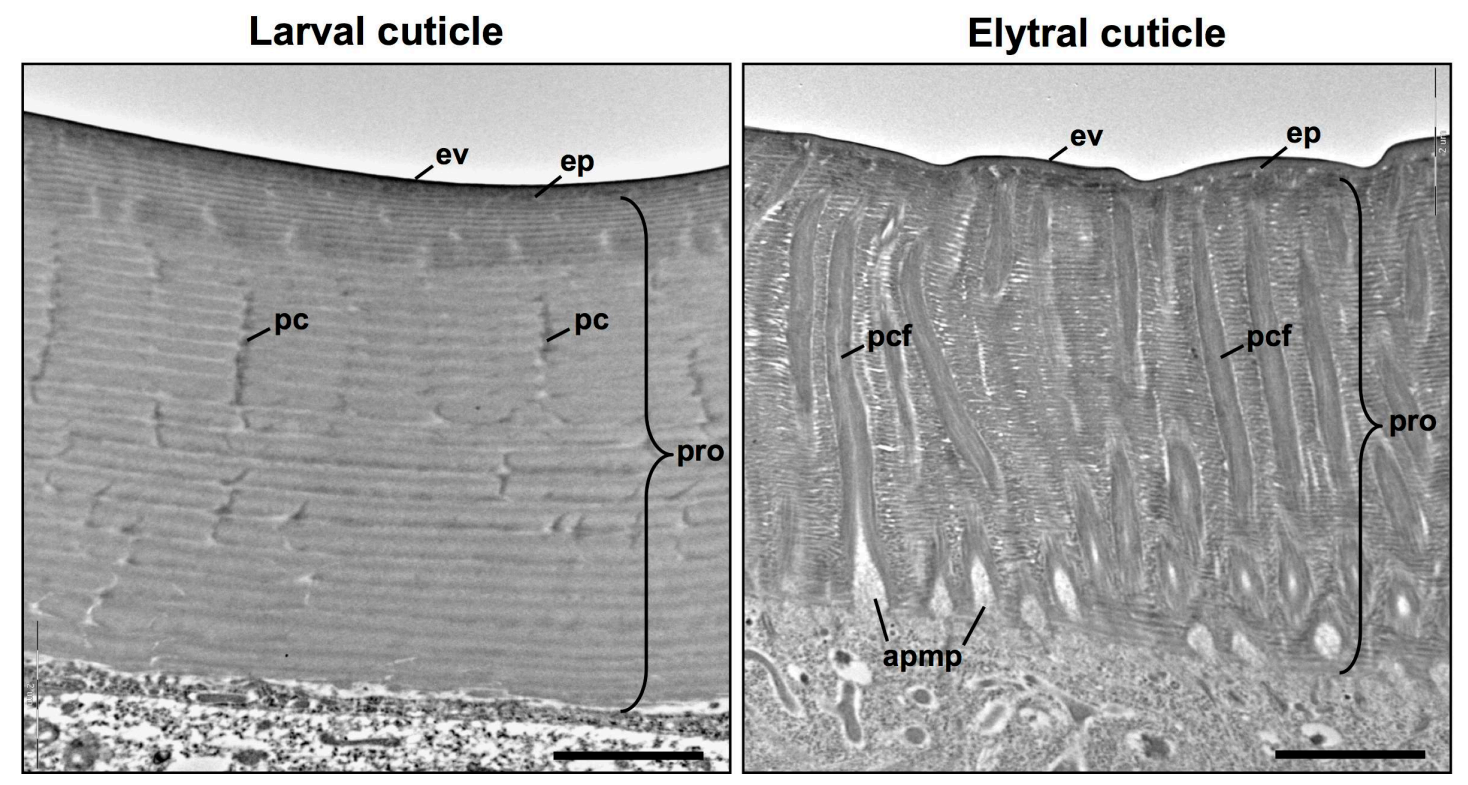


Fig. 3

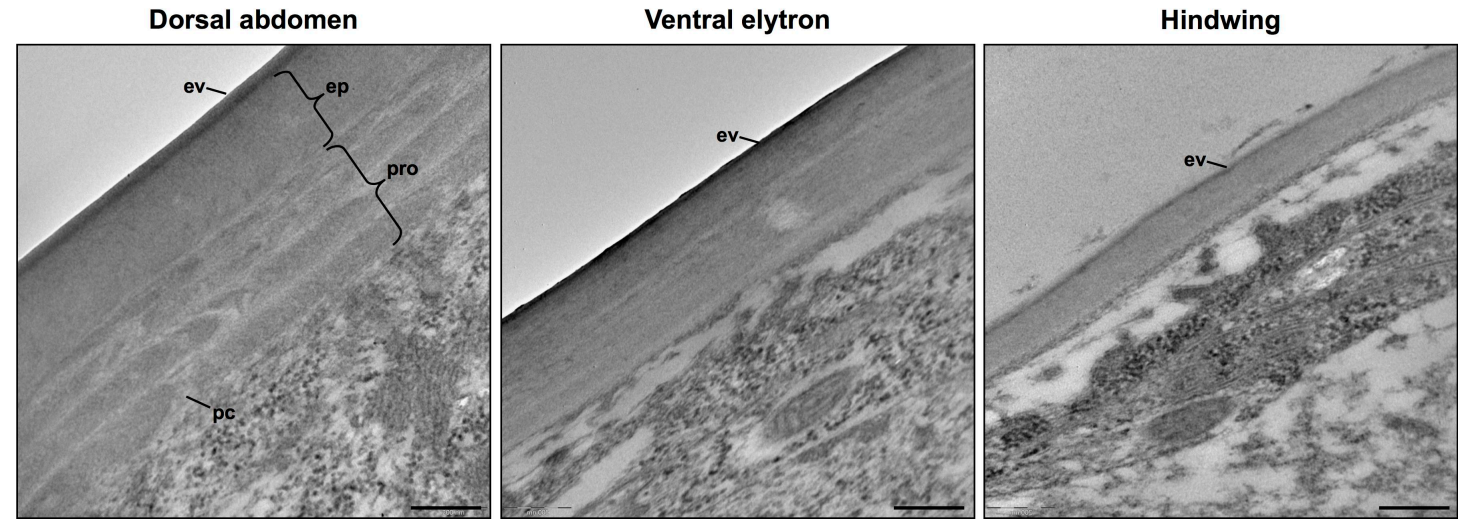


Fig. 4
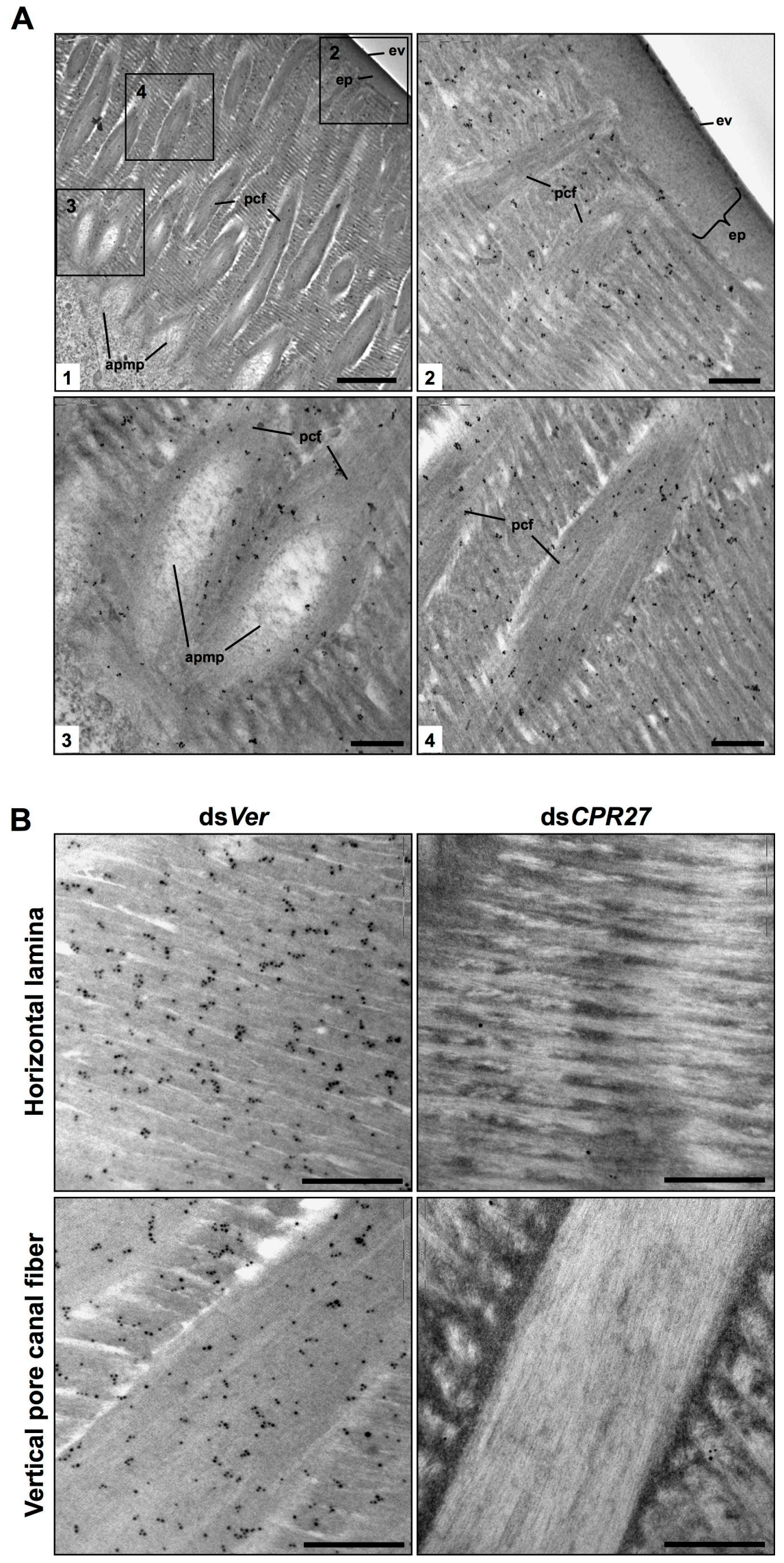
Fig. 5
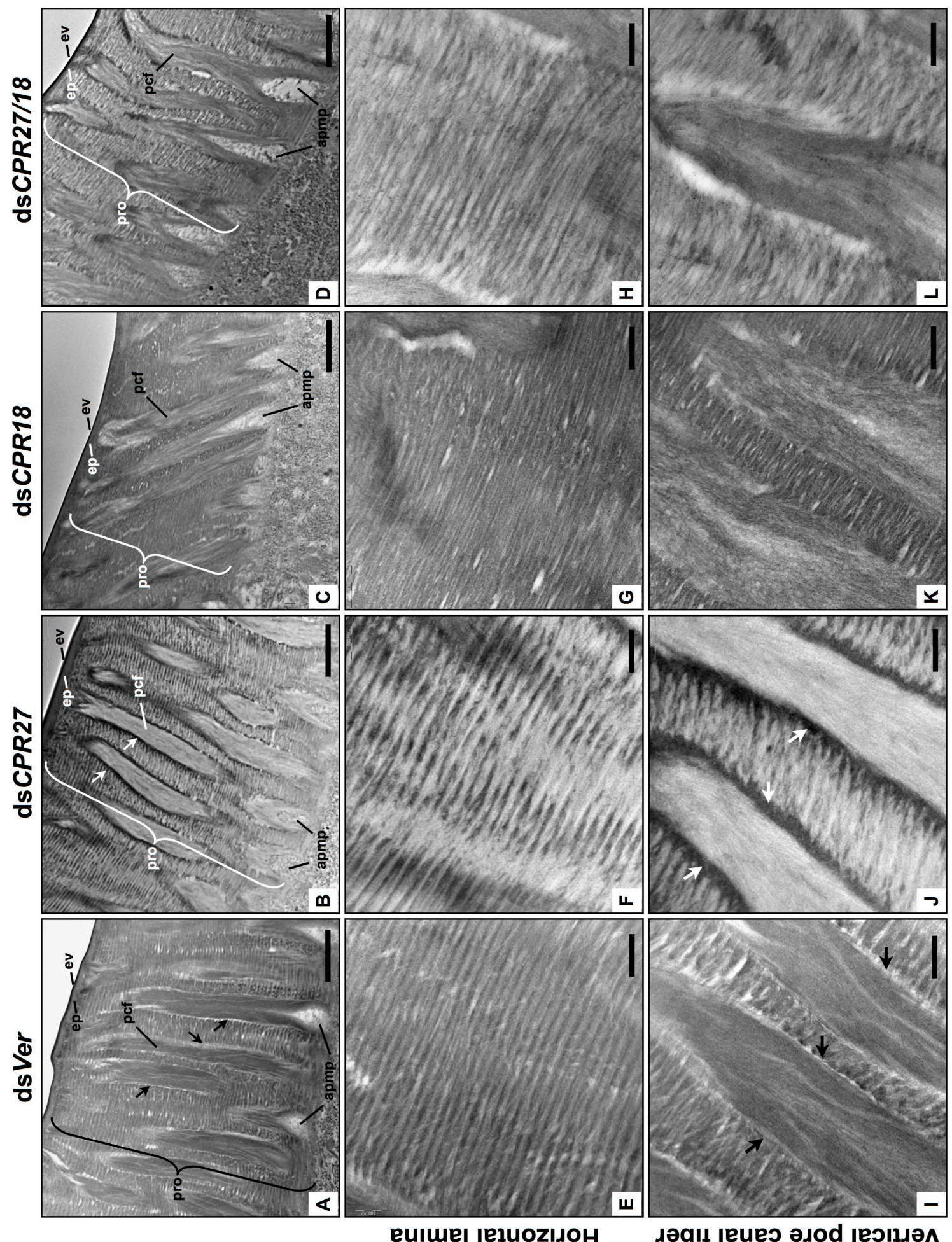

eu!ue| |ełuoz!joH 


\section{Supplementary Figures}

Supplementary Fig. 1
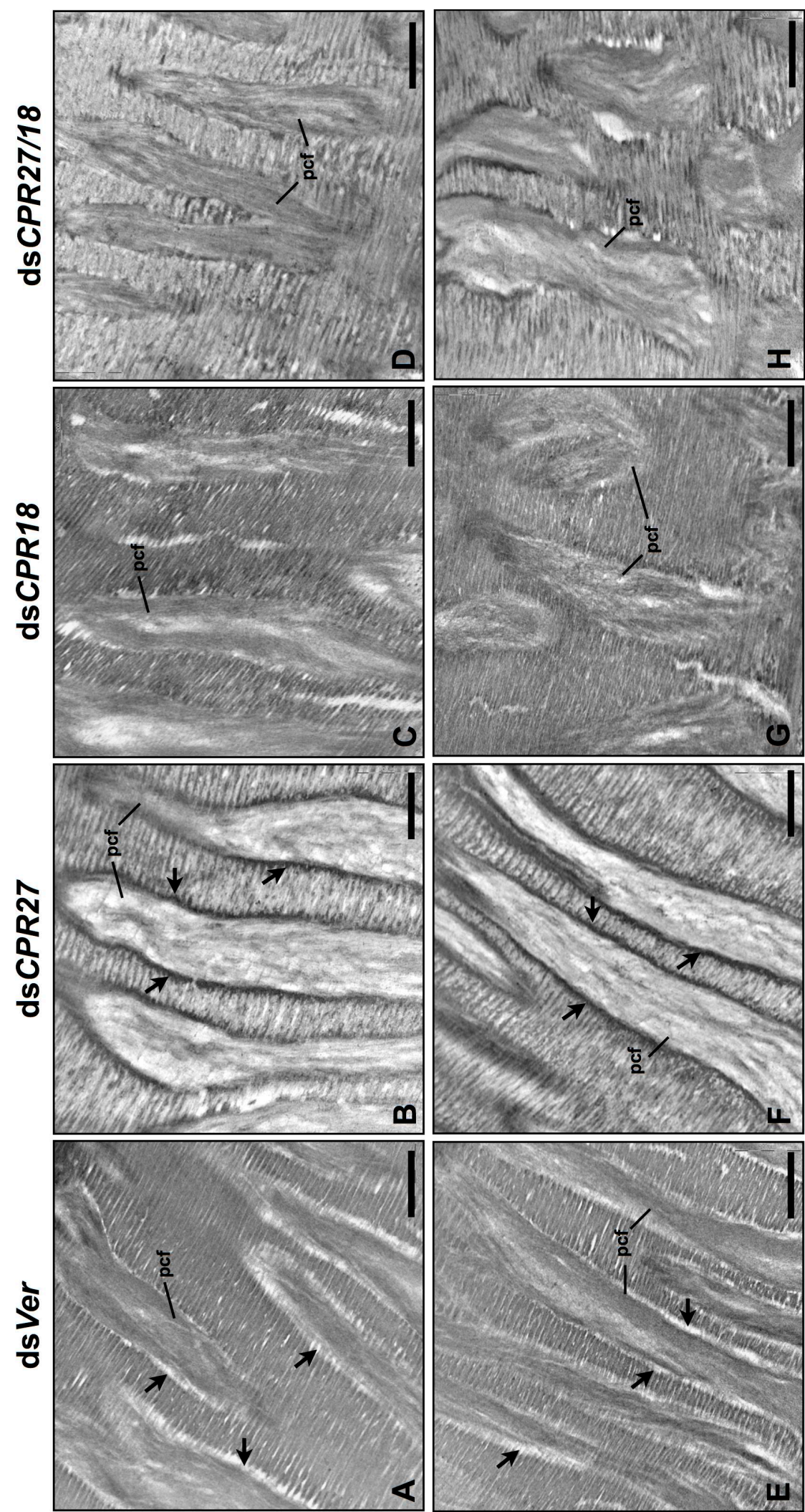

XeJOYI
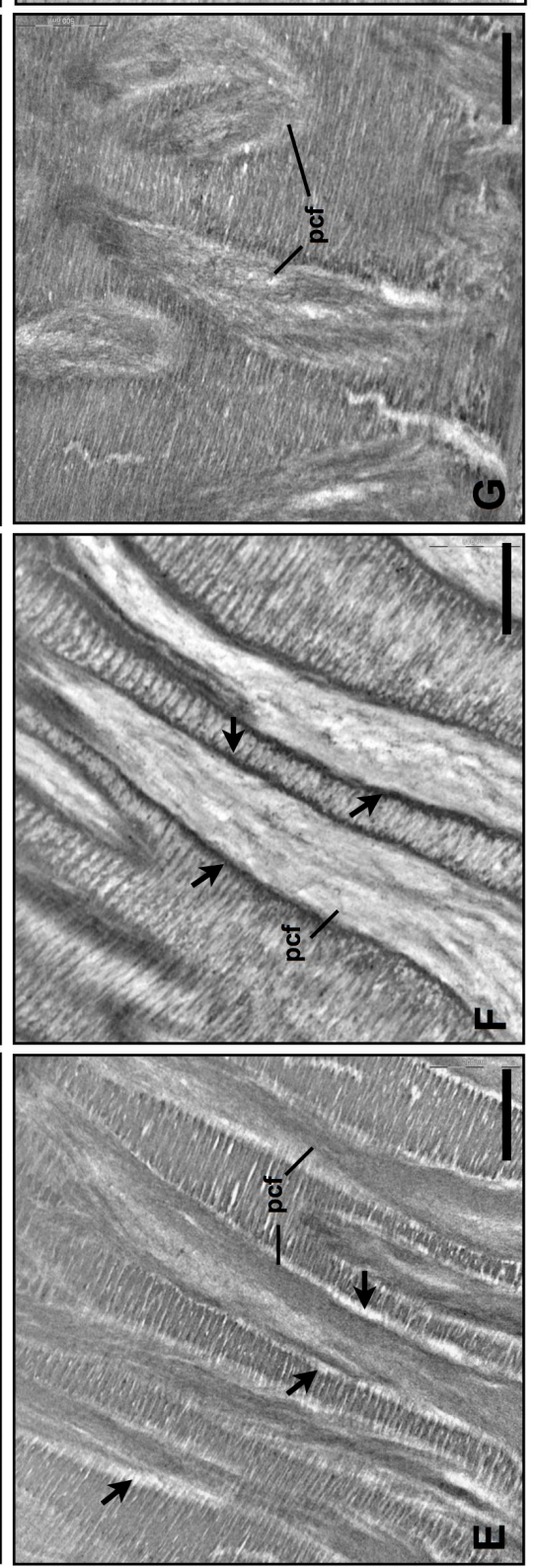

6ə7 
Supplementary Fig. 2
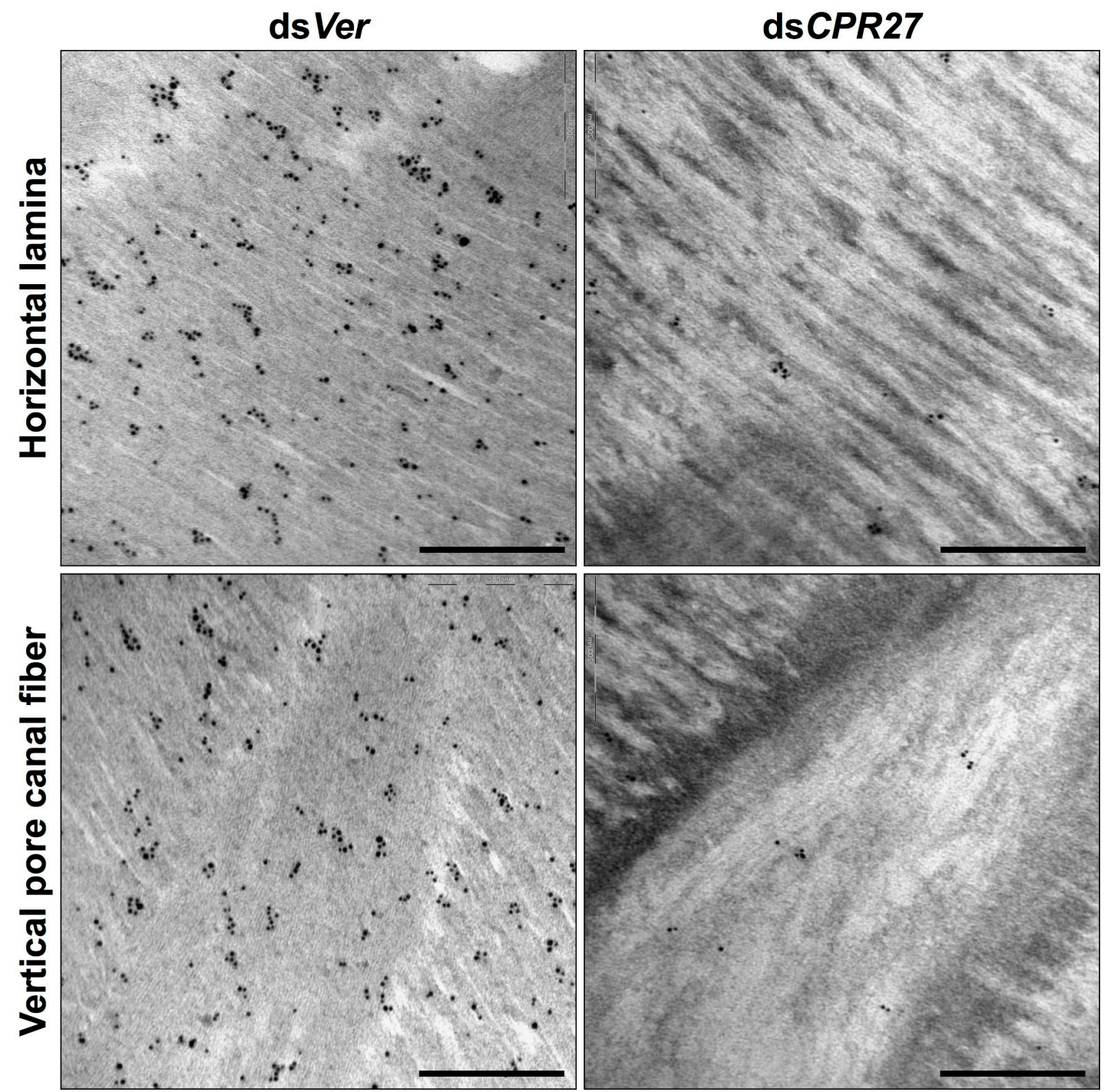
Supplementary Fig. 3

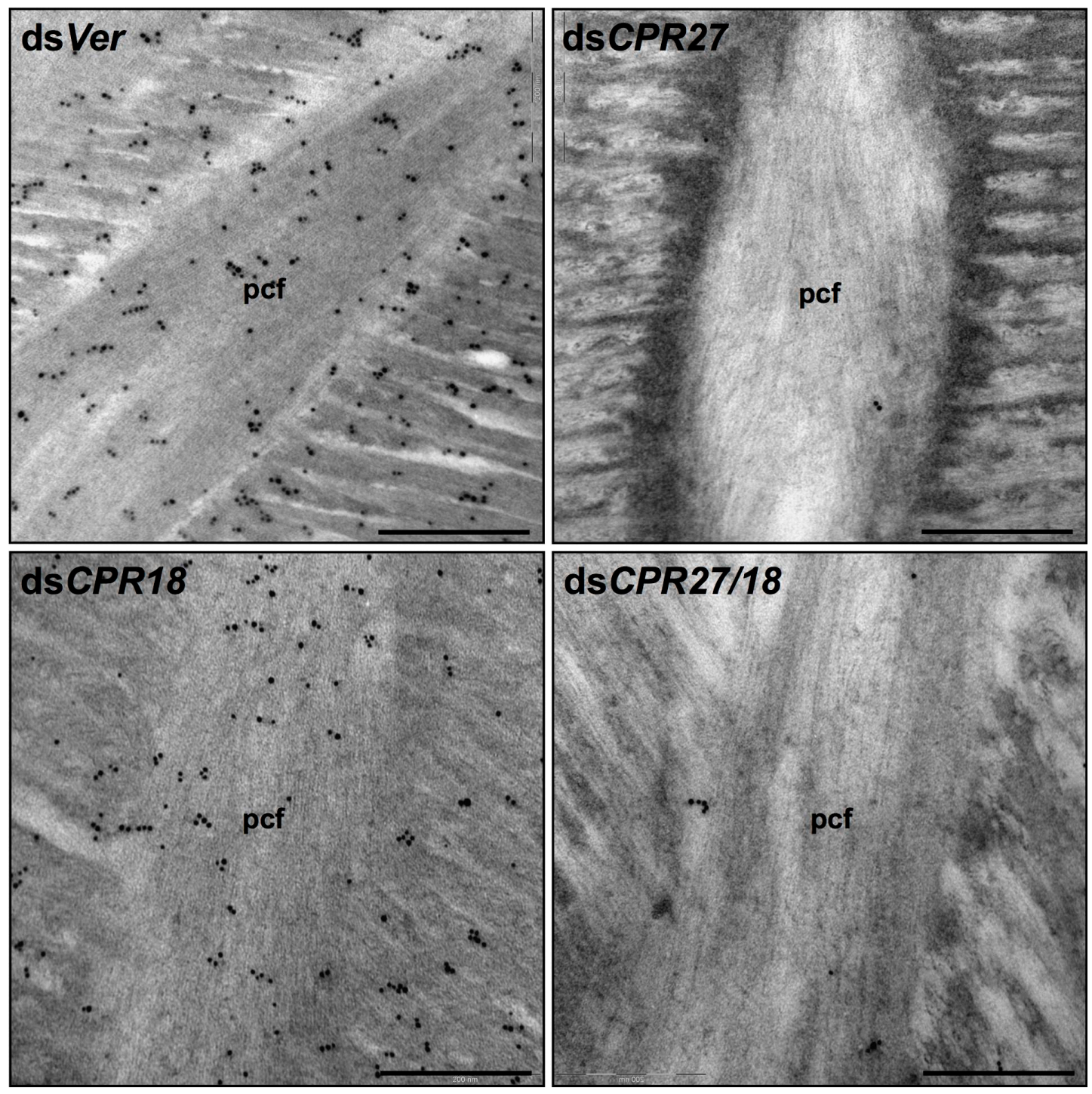

